15

\title{
Применение индукционных датчиков в исследованиях быстропротекающих процессов
}

\author{
(C) С.И. Герасимов, ${ }^{1,2,3,4}$ В.И. Ерофреев, ${ }^{3}$ А.В. Зубанков, ${ }^{1,2}$ В.А. Кикеев, ${ }^{3,4}$ Е.Г. Косяк, ${ }^{2}$ П.Г. Кузнецов, ${ }^{2}$ \\ B.В. Писецкий ${ }^{2}$
}

${ }^{1}$ Российский фредеральный ядерный центр - Всероссийский научно-исследовательский институт экспериментальной фризики,

607188 Саров, Нижегородская обл., Россия

${ }^{2}$ Саровский физико-технический институт НИЯУ МИФИ,

607186 Саров, Нижегородская обл., Россия

${ }^{3}$ Институт проблем машиностроения РАН - фрилиал Института прикладной ффизики РАН,

603024 Нижний Новгород, Россия

${ }^{4}$ Нижегородский государственный технический университет им. Р.Е. Алексеева,

603950 Нижний Новгород, Россия

e-mail: s.i.gerasimov@mail.ru

Поступило в Редакцию 13 ноября 2019 г.

В окончательной редакции 13 ноября 2019 г.

Принято к публикации 5 февраля 2020 г.

\begin{abstract}
При испытаниях на ракетном треке одной из наиболее сложных проблем является система управления и запуска пиротехнических средств в заданной координате. Представлены способ запуска и устройство для его осуществления, предназначенные для обеспечения срабатывания пиротехнических средств при разгоне ракетных поездов по направляющим ракетно-катапультирующего трека до гиперзвуковых скоростей с катапультированием объекта испытания в свободный полет. В основе способа заложен принцип формирования токовых импульсов для срабатывания пиротехнических средств движущихся ступеней ракетного поезда с применением индукционных датчиков. Этот же принцип позволяет реализовать бесконтактный способ запуска регистрирующих систем и устройство измерения средней скорости метаемого объекта в сплошных средах. В основе способа заложен принцип формирования запускающих сигналов (прямоугольных импульсов положительной полярности) для запуска регистрирующей аппаратуры с синхронизацией запуска по пути в заданной координате и измерение скорости метаемого объекта в момент пролета его через измерительное сечение. Приведены способы запуска регистрирующих систем и результаты, полученные в результате проведения гидродинамических и террадинамических экспериментов.
\end{abstract}

Ключевые слова: индукционный датчик, ракетный трек, аэробаллистический участок, гидродинамический участок, террадинамический участок.

DOI: 10.21883/JTF.2020.08.49550.365-19

\section{Введение}

Запуск в строгой последовательности линейных ступеней ракетных поездов (РП) и катапультирование объекта испытаний (ОИ) в свободный полет обеспечивает система запуска пиротехнических средств (ПС) ступеней РП.

Используемая в настоящее время система запуска ПС ступеней РП является системой контактного типа. Применяемая система проста в исполнении и эксплуатации и, что важно, обеспечивает выдачу исполнительных команд по пути движения РП, но она работоспособна при малых скоростях разгона, до $1200 \mathrm{~m} / \mathrm{s}$. В связи с этим актуальной задачей является создание системы, обеспечивающей бесконтактный запуск ПС РП.

Одной из важнейших проблем проведения аэробаллистических, гидродинамических и террадинамических испытаний является организация высокоточных систем хронографирования для определения скорости метаемого объекта (МО) времяпролетным способом и регистрации МО на участке свободного полета, особен- но высокоскоростного полета. Времяпролетный способ определения скорости и регистрация МО на траектории предусматривают необходимость фиксации по времени местоположения МО. Обычно для этих целей используются датчики контактного типа, а формирование синхронизирующего сигнала для регистрирующей аппаратуры производится по времени с учетом прогнозируемой скорости. При низкоскоростных испытаниях эта аппаратура работает достаточно успешно. При больших скоростях достаточно часто сопровождаются непредсказуемыми результатами. Использование датчиков контактного типа приводит к разрушению и отклонению МО от заданной траектории, а синхронизация по времени - к потере информации.

\section{Краткая характеристика бесконтактных индукционных датчиков}

Индукционные датчики (ИД) относятся к генераторному типу датчиков. Конструкции и назначения та- 
ких датчиков различны. Они могут использоваться для определения параметров переменных и стационарных магнитных полей.

В основе механизма формирования полезного сигнала лежит характеристика функции отклика $\mathscr{E}_{i}(t)$, возникающая в датчике в соответствии с законом электромагнитной индукции при изменении магнитного поля. $\mathscr{E}_{i}(t)$ зависит от скорости изменения магнитного потока, энергии магнитного поля, величины рабочего зазора между магнитом и датчиком и размеров МО. К достоинствам данного типа датчиков можно отнести простоту и прочность конструкции, отсутствие скользящих контактов, работу без источника питания и значительная чувствительность.

Датчики выполнены в виде многослойной катушки индуктивности с плотно прилегающими друг к другу витками со стальным сердечником.

\section{Способы применения бесконтактных индукционных датчиков}

Экспериментальные исследования бесконтактных индукционных датчиков проводились на многоцелевом испытательном комплексе и преследуют две основные цели:

- оценка возможности использования явления электромагнитной индукции в качестве источника управляющего сигнала запуска ПС линейных ступеней РП в прямых пусках ОИ на ракетном треке (РТ);

- определение средней скорости МО при пулеосколочных и осколочных испытаниях в плотных средах с измерением времени пролета их мерной базы.

Способ 1. Запуск ПС линейных ступеней РП на РТ. В основе способа заложен принцип формирования токовых импульсов для срабатывания ПС линейных ступеней РП при гиперзвуковых скоростях от бортового временного

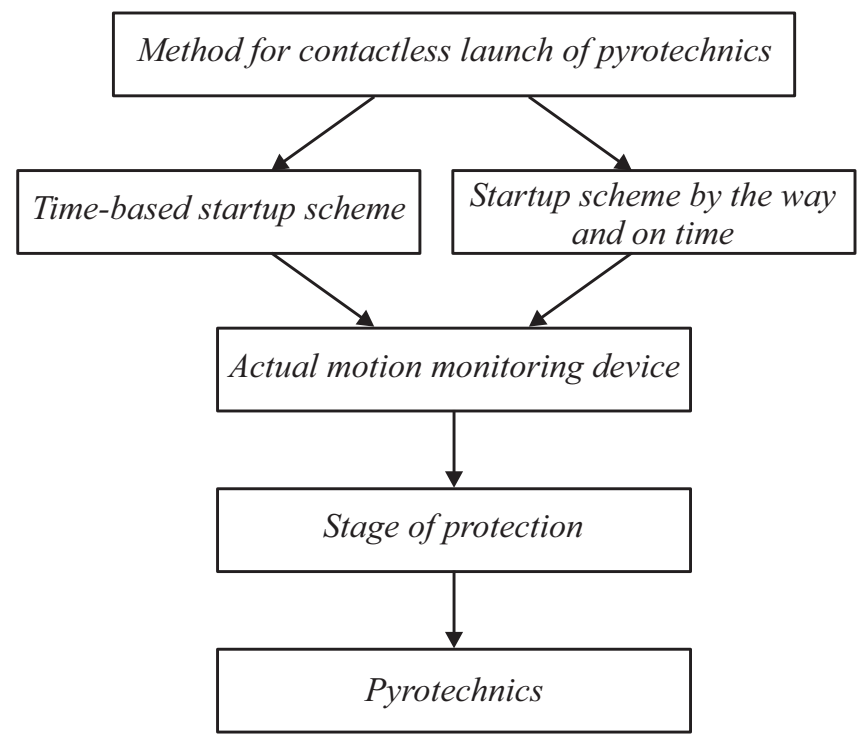

Рис. 1. Способ обеспечения срабатывания ПС.
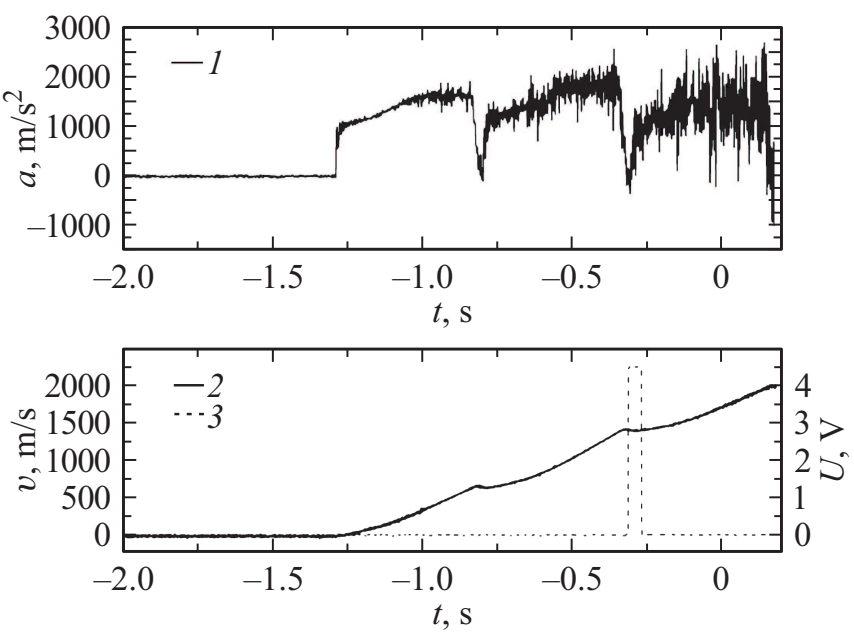

Рис. 2. Результаты экспериментальных исследований бесконтактной системы запуска ПС. 1 - график ускорения, $2-$ график скорости, 3 - сигнал на снятие ступени предохранения по скорости.
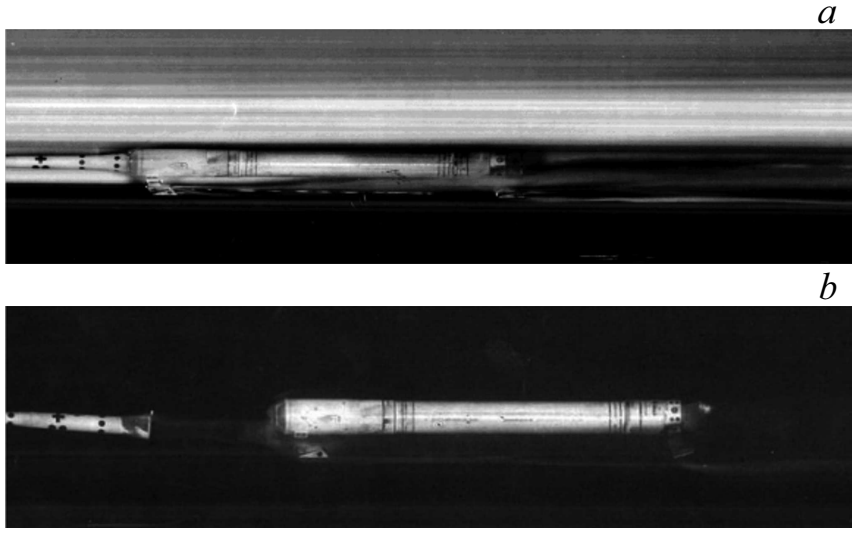

Рис. 3. Фотографии грузовой ступени РП с ОИ: $a-$ грузовая ступень РП с ОИ, $b$ - разделение грузовой ступени РП и ОИ.

устройства (запуск по времени) и отделение ОИ от средств разгона в свободный полет в заданной координате (запуск по пути) от бортовой схемы, формирующей сигнал запуска ПС, в момент прохода индукционного датчика мимо установленного на рельсовых направляющих постоянного магнита [1]. Учитывая ответственность и повышенные требования к исполнению команды на отделение ОИ, предусмотрено резервирование команды на срабатывание ПС от бортового временного устройства, но с приоритетом запуска по пути. Способ и устройство запуска ПС реализованы в виде бесконтактной системы запуска ПС [2] (рис. 1).

На ракетном треке проведены эксперименты по исследованию бесконтактной системы запуска ПС при высокоскоростных испытаниях. В ряде опытов РП оснащался радиотелеметрическим модулем, с использованием которого проводились бортовые измерения линейных ускорений, угловых скоростей и информационных сигналов с помощью наземных приемно-регистрирующих пунктов. 
В качестве примера полученной радиотелеметрической информации на рис. 2 представлены зависимости ускорения, скорости и информационных сигналов от времени движения РП, а на рис. 3 - фотографии грузовой ступени РП с ОИ.

Способ 2. Определение средней скорости МО на аэробаллистическом участке траектории при пулеосколочных и осколочных испытаниях с измерением времени пролета их мерной базы [3]. В основе способа заложен принцип формирования отклика от ИД, определение на мерной базе аэробаллистического участка средней скорости движения МО и организация запуска оптикофизической аппаратуры в момент пролета его через измерительное сечение (ИС). В качестве МО была выбрана пуля калибром $7.62 \mathrm{~mm}$, а выстрел производился из СВД.

Проведенные исследования касались в основном бесконтактного измерения средней скорости и запуска оптико-физической аппаратуры с использованием ИД, которые имеют преимущества перед датчиками контактного типа при высокоскоростных испытаниях. Кроме того, использование датчиков контактного типа приводит к разрушению и отклонению МО от заданной траектории, а синхронизация по времени - к потере информации. Отсутствие информации о МО на траектории не позволяет сделать надежных выводов о причинах аварий.

Однотипные бесконтактные ИД устанавливались в перпендикулярных плоскостях относительно друг друга, создавая при этом ИС $(S=230 \mathrm{~mm})$ на пути предполагаемой траектории полета МО. Напротив (в каждой из плоскостей ИС) от торца ИД на расстоянии $L=230 \mathrm{~mm}$ устанавливались постоянные магниты (ПМ) цилиндрической формы (марки $\mathrm{NdFeB}$ ), выполняющие функцию полесоздающего устройства [4].

При пролете МО ИС „датчик-магнит“ (мимо центров датчиков) в датчиках вырабатывался электрический

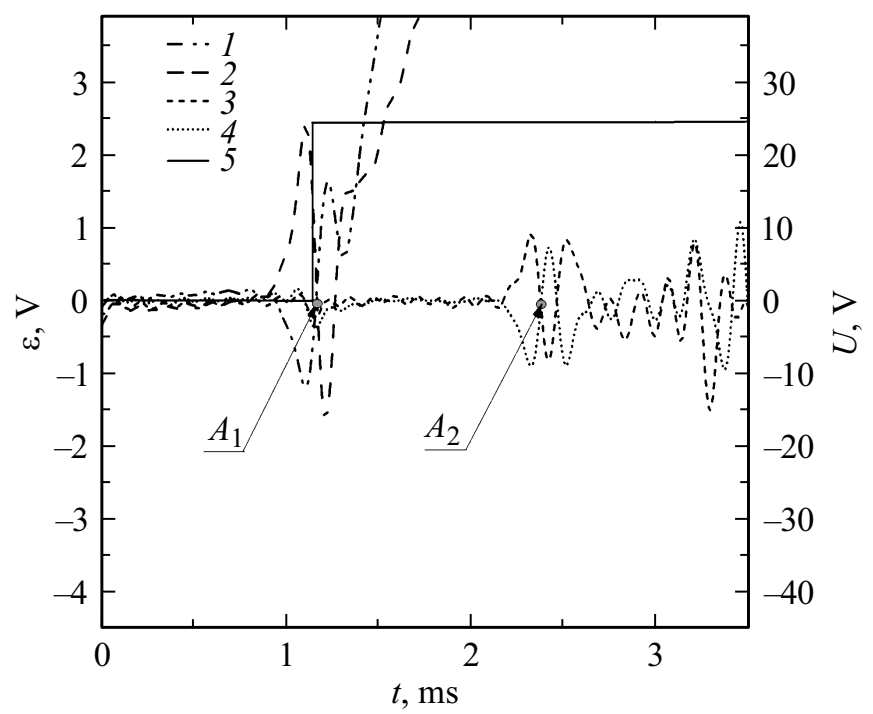

Рис. 4. Сигналы с индукционных датчиков $(1-4) ; 5-$ сигнал „Запуск регистрирующей аппаратуры“.

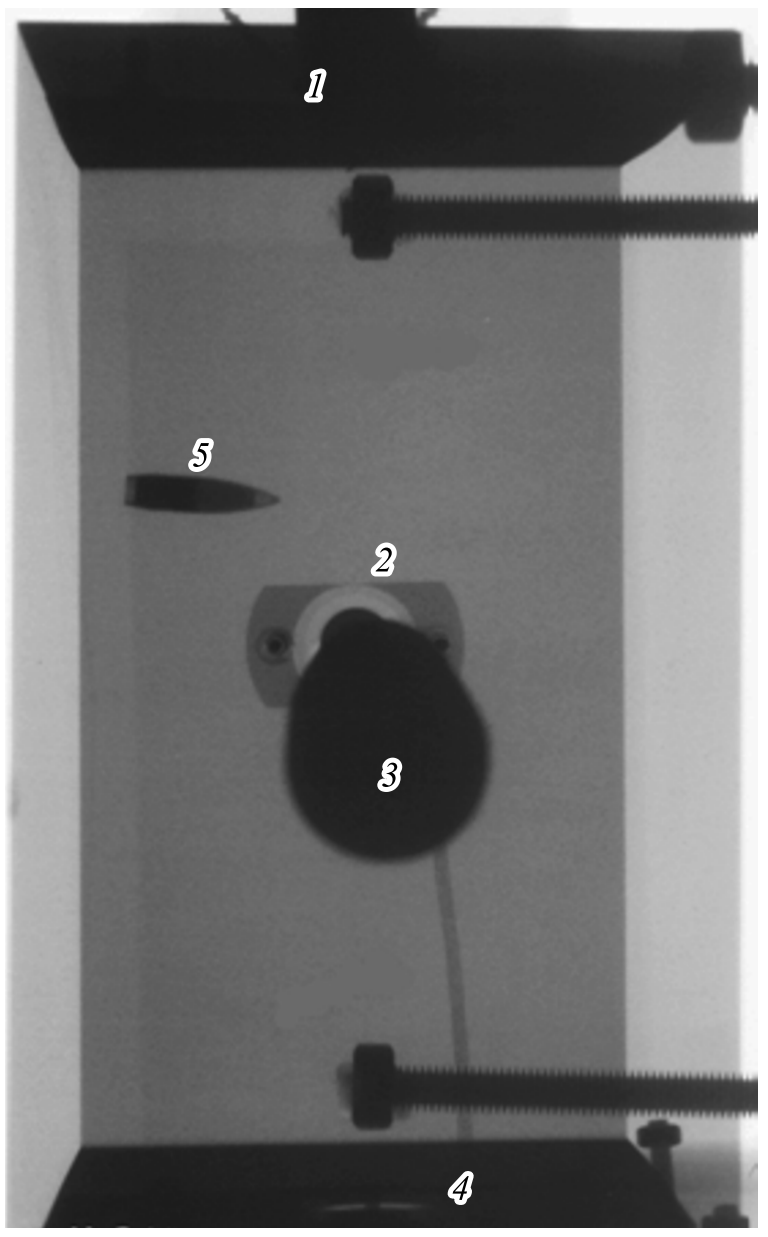

Рис. 5. Типовая рентгенограмма в области регистрации РА: индукционные датчики ИД1.1, ИД1.2 измерительного сечения ИС1 $(1,2)$; постоянные магниты $(3,4) ; 5-\mathrm{MO}$.

Таблица 1. Результаты измерений, полученные при проведении опыта

\begin{tabular}{c|c|c|c|c|c}
\hline $\begin{array}{c}\text { Bремя срабатывания датчиков относительно } \\
\text { сигнала „запуск регистратора“ }\end{array}$ & \multicolumn{2}{c}{$\begin{array}{c}\text { Скорость } \\
\text { МО по ИС }\end{array}$} \\
\hline ИД1.1 ИД1.2 & ИД2.1 & ИД2.2 & \multicolumn{2}{c}{$V, \mathrm{~m} / \mathrm{s}$} \\
\hline$t_{1}, \mathrm{~ms}$ & \multicolumn{2}{|c|}{$t_{2}, \mathrm{~ms}$} & ИС1 & ИС2 \\
\hline \multicolumn{2}{|c|}{2.376} & \multicolumn{2}{|c}{823.6}
\end{tabular}

импульсный сигнал. Запись электрических сигналов с датчиков во всех опытах производилась на цифровом запоминающем осциллографе.

На рис. 4 приведены типовые графические зависимости $\mathscr{E}(t)$ электрических сигналов с ИД на аэробаллистическом участке траектории движения МO, а на рис. 5 типовая рентгенограмма в области регистрации РА. Результаты измерений, полученные при проведении опыта, с указанием времен срабатывания ИД, представлены в табл. 1. 

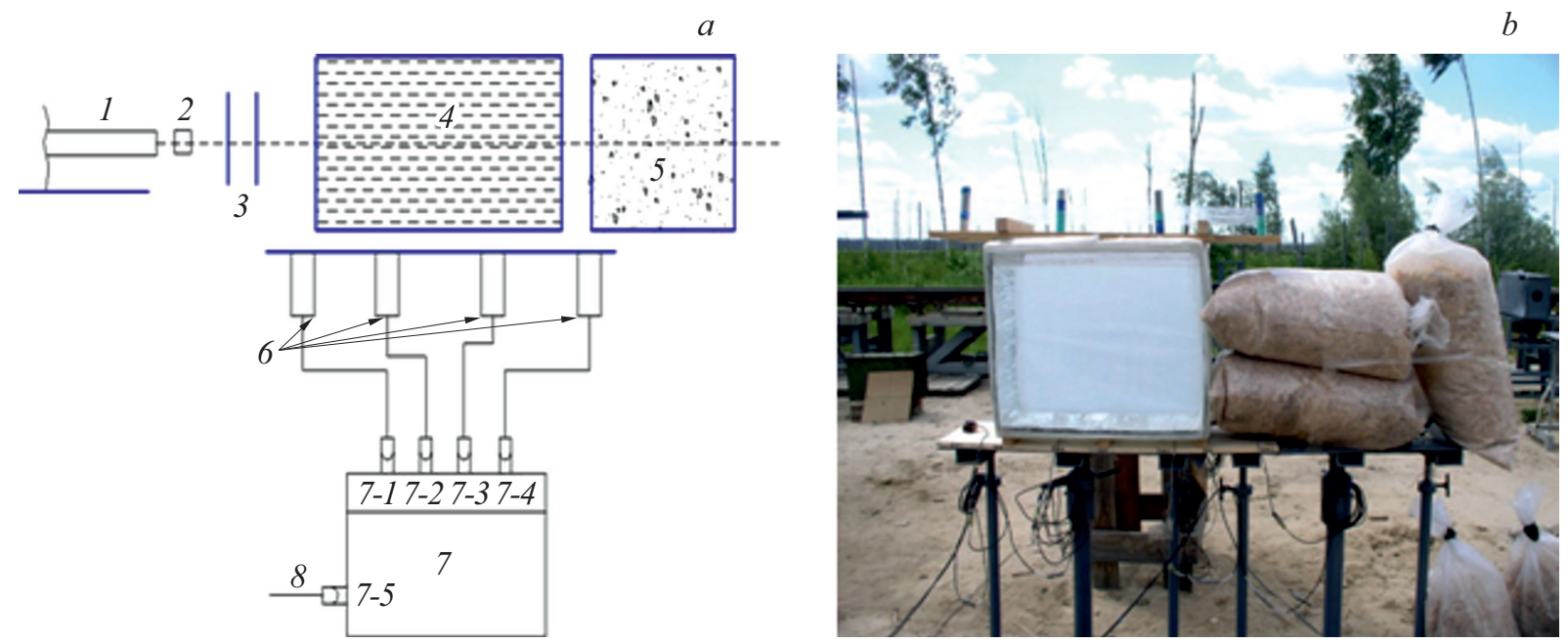

Рис. 6. Общий вид проведения эксперимента: $a$ - схема расстановки оборудования, $b$ - гидродинамический участок с ИД; $1-$ баллистическая установка, 2 - MO, 3 - контактные датчики, 4 - гидродинамический участок, 5 - уловитель, 6 - индукционные датчики, 7 - запоминающий осциллограф, 8 - сигнал запуска.

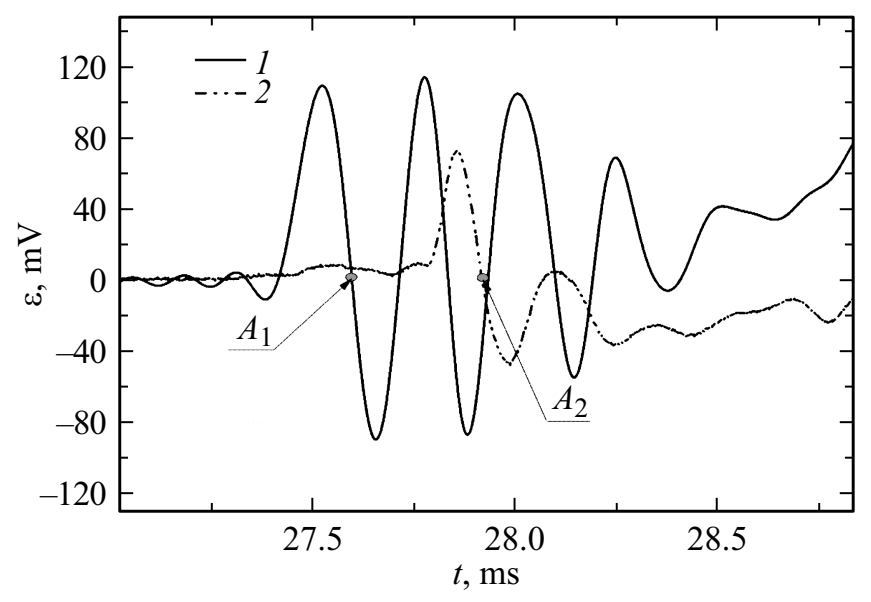

Рис. 7. Сигналы с индукционных датчиков $(1,2)$.

Таблица 2. Результаты измерений, полученные при проведении опыта

\begin{tabular}{|c|c|c|c|c|c|c|c|c|}
\hline \multicolumn{8}{|c|}{$\begin{array}{c}\text { Время срабатывания датчиков относительно } \\
\text { сигнала „запуск регистратора“/Расстояние } \\
\text { до датчиков относительно среза } \\
\text { ствола баллистической установки }\end{array}$} & \multirow{3}{*}{\begin{tabular}{|c}
$\begin{array}{c}\text { Ско- } \\
\text { рость } \\
\text { МО } \\
\text { в воде } \\
\text { по ИС }\end{array}$ \\
$\begin{array}{c}V, \\
\mathrm{~m} / \mathrm{s}\end{array}$
\end{tabular}} \\
\hline \multicolumn{2}{|c|}{ КД1 } & \multicolumn{2}{|c|}{ КД2 } & \multicolumn{2}{|c|}{ ИД2 } & \multicolumn{2}{|c|}{ ИД3 } & \\
\hline $\begin{array}{l}t_{1} \\
\mathrm{~ms}\end{array}$ & $\begin{array}{c}s_{1}, \\
\mathrm{~mm}\end{array}$ & $\begin{array}{l}t_{2} \\
\mathrm{~ms}\end{array}$ & $\begin{array}{c}s_{2}, \\
\mathrm{~mm}\end{array}$ & $\begin{array}{l}t_{3} \\
\mathrm{~ms}\end{array}$ & $\begin{array}{c}s_{3}, \\
\mathrm{~mm}\end{array}$ & $\begin{array}{l}t_{4} \\
\mathrm{~ms}\end{array}$ & $\begin{array}{l}s_{4}, \\
\mathrm{~mm}\end{array}$ & \\
\hline 6.118 & 3499 & 26.597 & 4538 & 27.595 & 5950 & \begin{tabular}{|l|}
27.917 \\
\end{tabular} & 6255 & 947.2 \\
\hline
\end{tabular}

Значение скорости МО при пролете его через измерительный участок определялось по формуле: $V=S / \Delta t$, где $S$ - расстояние между геометрическими центрами
ИД, $\Delta t=t_{2}-t_{1}-$ интервал времени пролета МО измерительного участка.

Вместе с тем за моменты времени $t_{1}$ и $t_{2}$, соответствующие нахождению МО в центре первого и второго измерительных сечений соответственно, приняты характерные точки $A_{1}$ и $A_{2}$ для определения интервала времени пролета МО измерительного участка.

Для определения средней скорости с минимальной погрешностью необходима установка датчиков строго ортогонально линии полета МО.

Сигнал „Запуск регистрирующей аппаратуры“ (рис. 4, сигнал 5) был сформирован в момент времени, когда МО находилось в плоскости ИС1.

Способ 3. Определение средней скорости МО на гидродинамическом участке траектории при пулеосколочных и осколочных испытаниях с измерением времени пролета их мерной базы. В основе способа заложен принцип формирования отклика от ИД и определение на гидродинамическом участке средней скорости движения МО в момент пролета его через ИС. Размеры аквариума с водой составляли $500 \times 300 \times 600 \mathrm{~mm}$. В качестве $\mathrm{MO}$ использовался стальной кубик (СТ45, $10 \times 10 \times 10 \mathrm{~mm}$, масса $12.5 \mathrm{~g}$ ). Общий вид проведения экспериментов представлен на рис. 6.

Однотипные бесконтактные ИД устанавливались на фиксированном расстоянии друг от друга, создавая при этом ИС на пути предполагаемой траектории полета МО. Напротив (в одном сечении) от торца ИД на расстоянии $L=500 \mathrm{~mm}$ устанавливались постоянные магниты $(M 1-M 4)$ цилиндрической формы (марки $\mathrm{NdFeB})$, выполняющие функцию полесоздающего устройства.

При пролете MO измерительных сечений „датчик-магнит“ (мимо центров датчиков) в датчиках вырабатывался электрический импульсный сигнал. Запись электрических сигналов с датчиков во всех опытах производилась на цифровом запоминающем 
$a$
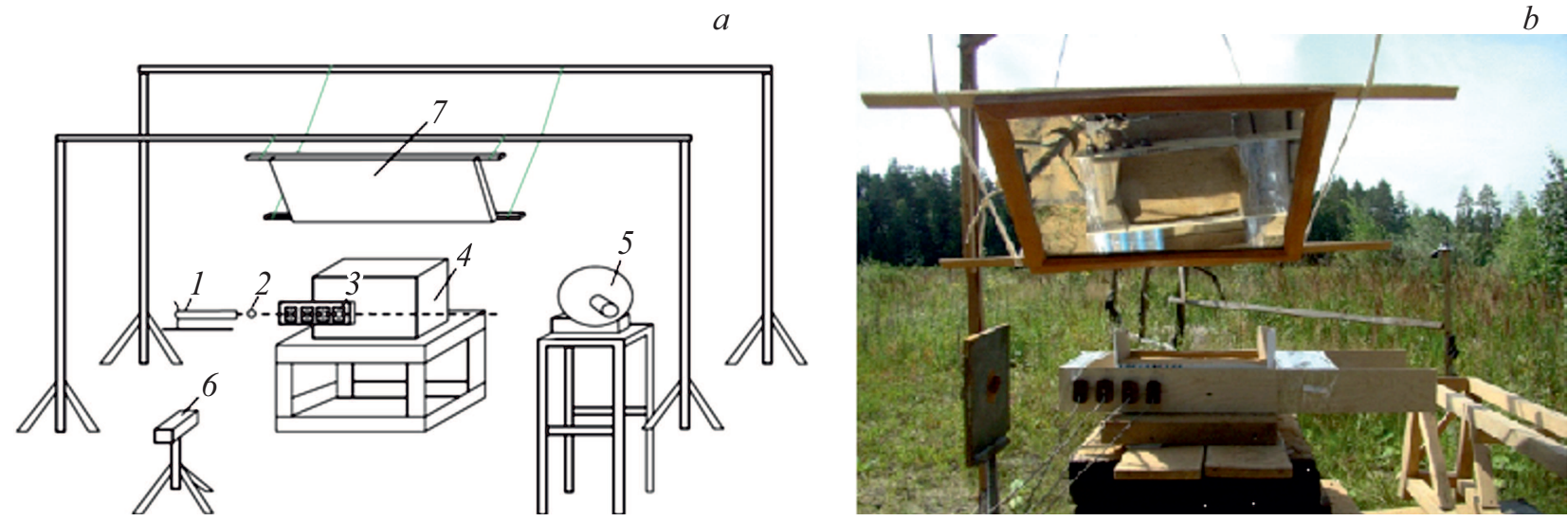

Рис. 8. Общий вид проведения эксперимента: $a$ - схема расстановки оборудования, $b-$ террадинамический участок с Ид; 1 - баллистическая установка, $2-\mathrm{MO}, 3$ - индукционные датчики, 4 - контейнер с песком, 5 - импульсный источник света, 6 - видеокамера, 7 - зеркало.

Таблица 3. Результаты измерений, полученные при проведении опыта

\begin{tabular}{c|c|c|c|c|c|c|c|c|c}
\hline \multicolumn{8}{c|}{$\begin{array}{c}\text { Время срабатывания датчиков относительно сигнала } \\
\text { „запуск регистратора“/Расстояние до датчиков относительно } \\
\text { среза ствола баллистической установки }\end{array}$} & $\begin{array}{c}\text { Скорость } \\
\text { МО в песке } \\
\text { по ИС }\end{array}$ \\
\hline \multicolumn{2}{c|}{ ИД1 } & \multicolumn{2}{c|}{ ИД2 } & \multicolumn{2}{c|}{ ИД3 } & \multicolumn{2}{c}{ ИД4 } & \multicolumn{2}{c}{$V, \mathrm{~ms}$} \\
\hline$t_{1}, \mathrm{~ms}$ & $s_{1}, \mathrm{~mm}$ & $t_{2}, \mathrm{~ms}$ & $s_{2}, \mathrm{~mm}$ & $t_{3}, \mathrm{~ms}$ & $s_{3}, \mathrm{~mm}$ & $t_{4}, \mathrm{~ms}$ & $s_{4}, \mathrm{~mm}$ & $2-3$ & $3-4$ \\
\hline 2.181 & 1130 & 2.216 & 1185 & 2.249 & 1230 & 2.288 & 1280 & 1363.6 & 1282.1
\end{tabular}

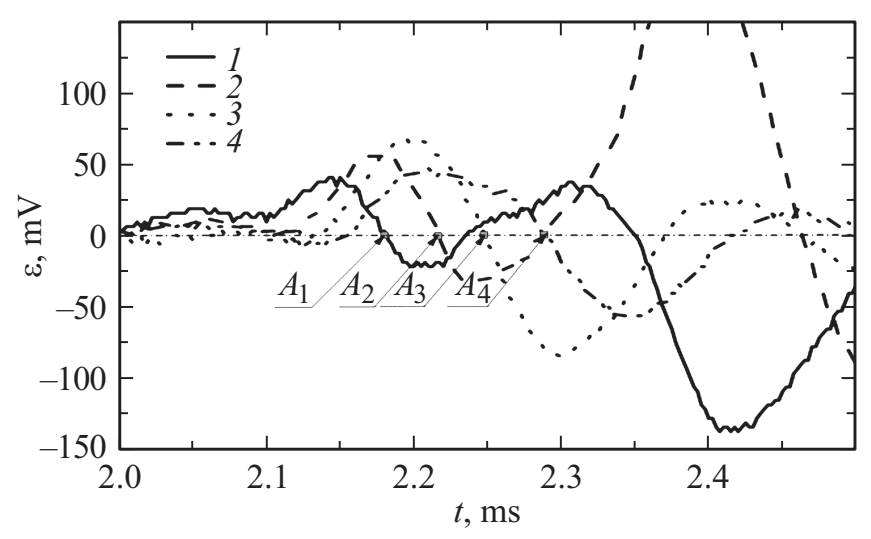

Рис. 9. Сигналы с индукционных датчиков $(1-4)$ : участок от датчика ИС1 до ИС2 - воздух, участки ИС2-ИС3, ИС $3-$ ИС 4 - песок.

осциллографе. Результаты измерений, полученные при проведении опыта с указанием времен срабатывания датчиковой аппаратуры, представлены в табл. 2, а графические зависимости $\mathscr{E}(t)$ электрических сигналов с ИД представлены на рис. 7.

Способ 4. Определение средней скорости МO на террадинамическом участке траектории при пулеосколочных и осколочных испытаниях с измерением времени пролета их мерной базы.
Способ, представленный на рис. 8, отличается от способа 3 тем, что средняя скорость движения МО в момент пролета его через ИС определялась на аэробаллистическом и террадинамическом участках траектории (заявка на изобретение RU № 2019101542, приоритет 21.01.2019). Размеры преграды с песком составляли $100 \times 230 \times 300 \mathrm{~mm}$. В качестве МО использовался циркониевый шарик $(d=10 \mathrm{~mm}$, масса $12.5 \mathrm{~g})$.

Бесконтактные ИД устанавливались на фиксированном расстоянии друг от друга, создавая при этом ИС $(S=50 \mathrm{~mm})$ на пути предполагаемой траектории полета МО. Напротив (в одном сечении) от торца ИД на расстоянии $L=230 \mathrm{~mm}$ устанавливались постоянные магниты $(M 1-M 4)$ цилиндрической формы (марки $\mathrm{NdFeB}$ ), выполняющие функцию полесоздающего устройства.

При пролете MO измерительных сечений „датчик-магнит“ (мимо центров датчиков) в датчиках вырабатывался электрический импульсный сигнал. Запись электрических сигналов с датчиков во всех опытах производилась на цифровом запоминающем осциллографе.

Результаты измерений, полученные при проведении опыта, с указанием времен срабатывания датчиковой аппаратуры, представлены в табл. 3, графические зависимости $\mathscr{E}(t)$ электрических сигналов с ИД на аэробаллистическом и террадинамическом участках траектории движения МО представлены на рис. 9. 
Сигналы с датчиков ИС ${ }_{1}-\mathrm{CC}_{4}$ идентичны по форме и длительности, при этом характерные точки $A_{1}-A_{4}$ на зависимости $\varepsilon(t)$, в которых осуществляется переход через нуль наведенной в ИД в соответствии с законом электромагнитной индукции электродвижущей силы ЭДС, физически соответствуют области с максимальным значением магнитного потока.

В этой связи за моменты времени $t_{1}-t_{4}$, соответствующие нахождению МО в центре первого, второго, третьего и четвертого измерительных сечений соответственно, приняты характерные точки $A_{1}-A_{4}$ для определения интервалов времени пролета МО измерительного участка.

Значения скорости МО при пролете его через измерительные участки определялись по формуле: $V_{i}=S_{i} / \Delta t_{i}$, где $S_{i}$ - расстояние между геометрическими центрами ИД, $\Delta t_{i}=t_{i+1}-t_{i}-$ интервал времени пролета МО измерительного участка.

\section{Заключение}

Анализ результатов применения бесконтактных индукционных датчиков показал, что система „датчик-магнит“ реализует методику запуска ПС на РТ и методику определения средней скорости МО на стенде пулеосколочных и осколочных испытаний.

В этой связи бесконтактные индукционные датчики могут быть использованы в качестве источника управляющего сигнала запуска ПС линейных ступеней РП в прямых пусках ОИ на РТ и с целью определения средней скорости ударника при пулеосколочных и осколочных испытаниях в плотных средах с измерением времени пролета их мерной базы.

\section{Финансирование работы}

Работа выполнялась при поддержке грантов РФФИ (проекты № 18-08-00715, 18-29-10073).

\section{Конфликт интересов}

Авторы заявляют, что у них нет конфликта интересов.

\section{Список литературы}

[1] Герасимов С.И., Зубанков А.В., Кикеев В.А. // Журнал датчики и системы. 2018. № 10. С. 27-33.

[2] Патент РФ № 2476712. Способ запуска пиротехнических устройств и устройство для его осуществления. / А.В. Зубанков, Ю.А. Кирдяшкин, И.И. Кортюков, В.А. Николаев, В.В. Страбыкин, М.А. Хайруллин. Бюл. 2013. № 6.

[3] Герасимов С.И., Зубанков А.В. // Журнал приборы и техника эксперимента. 2019. № 3. С. 38-40.

[4] Патент РФ № 2698531. Способ измерения времени пролета метаемым телом мерной базы и устройство для его осуществления. С.И. Герасимов, А.В. Зубанков, А.В. Казаков, В.А. Николаев, Е.В. Шукшин. Бюл. 2019. № 25. 